\title{
Study on Seismic Behavior of Concrete-filled square steel tube column with core column -Steel Beam Joints
}

\author{
Wang Meng ${ }^{1, \mathrm{~b}}$, Tao $\mathrm{Yi}^{1,2, \mathrm{a}^{*}}$ \\ ${ }^{1}$ School of Civil Engineering, Xi'an University of Architecture and Technology, Xi'an, Shaanxi, China \\ ${ }^{2}$ State Key Laboratory of Green Building in Western China, Xi' an University of Architecture and Technology, Xi'an, Shaanxi, China
}

\begin{abstract}
Summary: This paper has carried out the quasi-static tests of five specimens of FRP-UHPC column-steel beam joints with core columns, and the extensive parameter analysis of the joints by numerical simulation. The results show that the Concrete-filled square steel tube column with core column -Steel Beam Joints have strong bearing capacity. It has excellent deformability, stiffness and energy dissipation capacity, and works well under the condition of high axial compression ratio. The bearing capacity of the replacement beam specimen does not deteriorate significantly, which indicates that the Concrete-filled square steel tube column with core column -Steel Beam Joints is replaceable.
\end{abstract}

\section{Preface}

As the most commonly used form of connection in semi-rigid joints, high-strength bolted connections have good seismic performance and manageable quality of connection, and can be processed in advance to realize on-site assembly construction and speed up construction progress ${ }^{[1]}$. Zong Zhouhong et al. ${ }^{[2]}$ found that the seismic performance of joints with core columns is better than that of ordinary welded joints. Wang Xiantie et al. ${ }^{[3]}$ conducted a seismic test of Concrete-filled square steel tube column with core column -Steel Beam Joints and found that the energy dissipation capacity of thin end-plate joints can be obviously improved by setting stiffeners. At present, the research on the seismic performance of steel-concrete-FRP-UHPC column (SCFU column) -steel beam joints with built-in high-strength core columns has not been carried out.

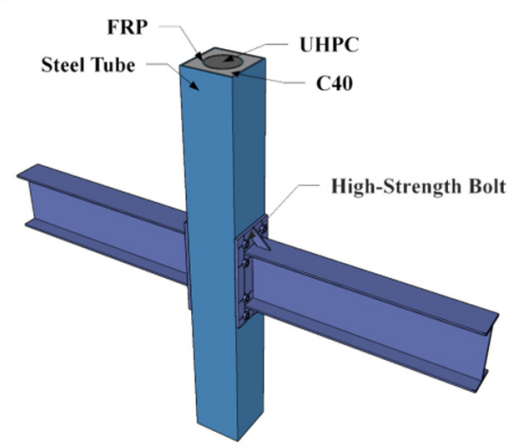

Figure 1 Schematic diagram of joints

In order to solve the problems of high requirements on structural mechanical properties and difficulty in construction of high-rise and super-high-rise buildings, this paper combines the characteristics of new
FRP-UHPC columns such as high ductility, high bearing capacity and convenience for beam-column joint connection, and the assemblability of end-plate-bolt connection joints, and proposes the concrete-filled steel tubular column-steel beam joints with core columns, as shown in Figure 1.

\section{Overview of the Tests}

\subsection{Specimen Design}

The FRP-UHPC column is a square section with a sectional size of $250 \mathrm{~mm} \times 250 \mathrm{~mm}$. The outer steel tubular column is $8 \mathrm{~mm}$ thick and the column height $\mathrm{h}$ is $1800 \mathrm{~mm}$. The core column uses GFRP tube to constrain UHPC column. The section specification of steel I-beam is $\mathrm{HN} 300 \mathrm{~mm} \times 150 \mathrm{~mm} \times 6.5 \mathrm{~mm} \times 9 \mathrm{~mm}$, and the length of steel beam is $1100 \mathrm{~mm}$. The dimension of the end plate is $480 \mathrm{~mm} \times 250 \mathrm{~mm} \times 25 \mathrm{~mm}$, and that of the end plate stiffener is $90 \mathrm{~mm} \times 90 \mathrm{~mm} \times 5 \mathrm{~mm}$. The joint detail dimensions are shown in Figure 2.

In the paper, four joint specimens were designed for quasi-static loading test based on three parameters: axial compression ratio, number of GFRP tube layers, and presence or absence of core columns to study the influence of each parameter on the seismic performance. A group of replacement beams were set to study the repairability of this structure after earthquake.

\footnotetext{
"Corresponding author: ${ }^{\mathrm{a} y}$.tao@xauat.edu.cn

bwm824742676@163.com
} 


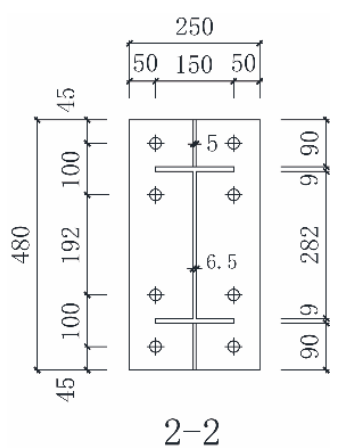

Figure 2 Joint detail dimensions

Table 1 Overview of the specimen

\begin{tabular}{|c|c|c|c|c|}
\hline $\begin{array}{c}\text { Specimen } \\
\text { No. }\end{array}$ & $n$ & $\begin{array}{c}\text { Core } \\
\text { column } \\
\text { Diameter } \\
/ \mathrm{mm}\end{array}$ & $\begin{array}{c}\text { FRP } \\
\text { Number } \\
\text { of } \\
\text { Layers }\end{array}$ & $\begin{array}{c}\text { Axial } \\
\text { compression } \\
\text { Load }\end{array}$ \\
\hline $100-10-0.3$ & 0.3 & 100 & 10 & $1382 \mathrm{kN}$ \\
\hline $100-10-0.6$ & 0.6 & 100 & 10 & $2764 \mathrm{kN}$ \\
\hline $100-8-0.6$ & 0.6 & 100 & 8 & $2751 \mathrm{kN}$ \\
\hline $100-8-0.6-\mathrm{C}$ & 0.6 & 100 & 8 & $2751 \mathrm{kN}$ \\
\hline $0-0-0.6$ & 0.6 & 0 & 0 & $2282 \mathrm{kN}$ \\
\hline
\end{tabular}

\subsection{Material Properties}

The sandwich concrete is $\mathrm{C} 40$ concrete with crushed stones, with the three-dimensional compressive strength of $46.5 \mathrm{MPa}$ and elastic modulus of $32.5 \mathrm{GPa}$. According to the testing method of "Reactive Powder Concrete" GB/T31387 -2015 $5^{[4]}$, the compressive strength and elastic modulus of UHPC cube measured are $160.5 \mathrm{MPa}$ and 45.2 GPa. The bolt adopts friction type high-strength bolt with nominal diameter M20 and strength grade 10.9. The steel adopts Q235 steel, and the material property data are shown in Table 2. The winding angle of GFRP tube is 80 , and the circumferential tensile test is carried out by splitting disc method. The results are shown in Table 3.

Table 2 Test results of steel properties

\begin{tabular}{|c|c|c|}
\hline $\begin{array}{c}\text { Steel } \\
\text { thickness } \\
/ \mathrm{mm}\end{array}$ & $\begin{array}{c}\text { Yield strength } \\
f_{y} / M P a\end{array}$ & $\begin{array}{c}\text { Tensile strength } \\
f_{u} / M P a\end{array}$ \\
\hline 5 & 272.75 & 403.78 \\
\hline 6.5 & 289.73 & 431.51 \\
\hline 8 & 334.99 & 462.34 \\
\hline 9 & 240.08 & 392.70 \\
\hline 25 & 307.61 & 435.89 \\
\hline
\end{tabular}

Table 3 Test results of GFRP properties

\begin{tabular}{|c|c|c|c|}
\hline Thickness & $\begin{array}{c}\text { Circumferential } \\
\text { ultimate } \\
t_{f} / \mathrm{mm}\end{array}$ & $\begin{array}{c}\text { Circumferential } \\
\text { ultimate tensile } \\
\text { strength } \\
\varepsilon_{h}\end{array}$ & $\begin{array}{c}\text { Poisson's } \\
\text { ratio } \\
v_{h} / \mathrm{MPa}\end{array}$ \\
\hline 3.13 & 0.0204 & 918.6 & 0.29 \\
\hline 3.57 & 0.0210 & 926.8 & 0.29 \\
\hline
\end{tabular}

\subsection{Loading Device and Measuring Scheme}

This test was carried out in the Key Laboratory of Structural Engineering and Seismic Resistance of Ministry of Education, Xi'an University of Architecture and Technology. Axial compression load

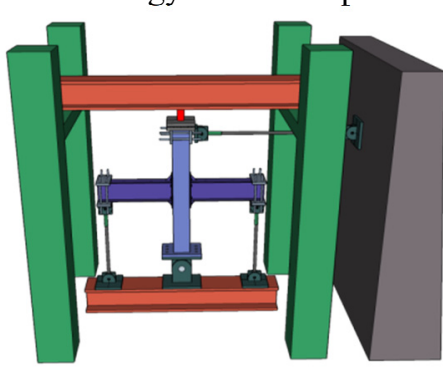

(a) Loading device

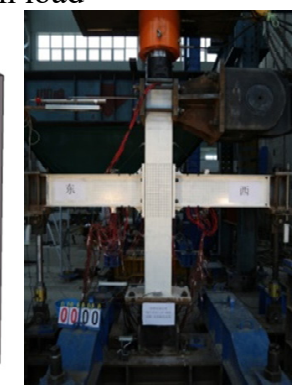

(b) Testing site
Figure 3 Loading device

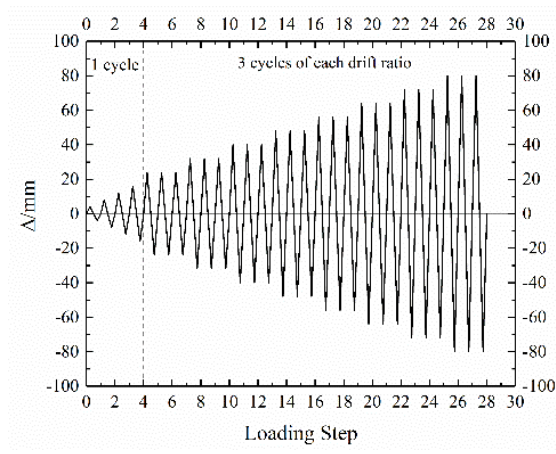

Figure 4 Loading system

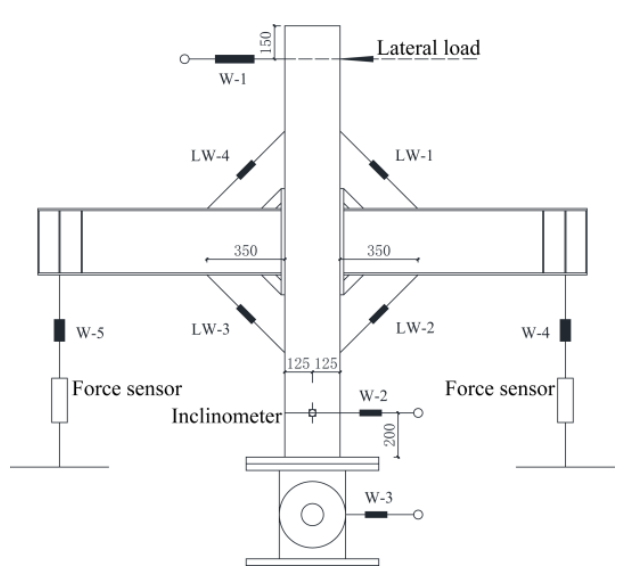

Figure 5 Layout of measuring points

is applied to the top of the column with $5000 \mathrm{kN}$ hydraulic jack, and lateral load is applied with $1000 \mathrm{kN}$ 
MTS hydraulic servo actuator. The loading device is shown in Figure 3, the loading system is shown in Figure 4 , and the layout of measuring points is shown in Figure 5 .

\section{Testing Phenomena and Failure Modes}

During the loading process, for each specimen, the flange of the steel I-beam first turns drum-like, and then the web also turns drum-like. The stiffener buckles due to the increase of the joint angle. At the same time, the existence of the stiffener also makes the plastic hinge of the steel I-beam move outward, forming a plastic hinge at a position $0.5 \sim 1$ times the beam height from the end plate. When each specimen is damaged, the steel beam has serious out-of-plane torsion, and the end of each specimen is slightly deformed after some high-strength bolts are removed. The test results show that the flange of the specimen buckles earlier under high axial compression ratio, and the column surface in the joint area has relatively larger drum-like curvature. The failure degree of the specimen without core column is greater. However, the failure phenomenon of the replacement beam specimen is basically the same as that of the original specimen. Figure 6 shows the failure phenomena of the typical specimen 100-8-0.6.

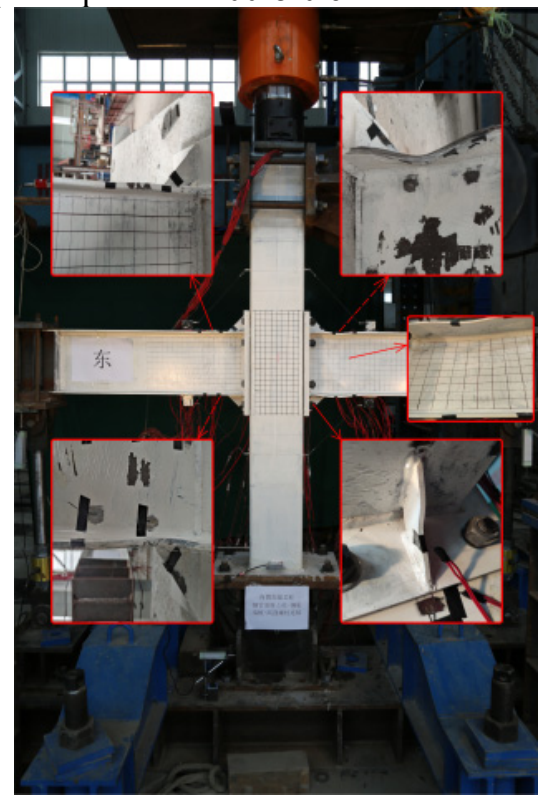

Figure 6 Failure mode of specimen 100-8-0.6

\section{Testing Data and Analysis}

\subsection{Hysteretic Curves}

Hysteretic curves of specimen are shown in Figure 7. It can be seen from the figure that the hysteretic curves of each specimen are fully spindle-shaped without pinching, which indicates that the seismic performance of the joints with core columns is good. The hysteretic curve of specimens with high axial compression ratio is relatively plumper, indicating that the energy dissipation capacity is better. The hysteretic curve of specimen 100-8-0.6 is plumper than that of specimen 100-8-0.6-C, because the FRP-UHPC column replacing beam specimen has certain plastic damage of steel tube and concrete cracking, and thus the energy dissipation capacity is reduced.

Because the specimen can't be perfectly tight during installation, a "stair" curve with displacement changing and load unchanged appears during the loading process.

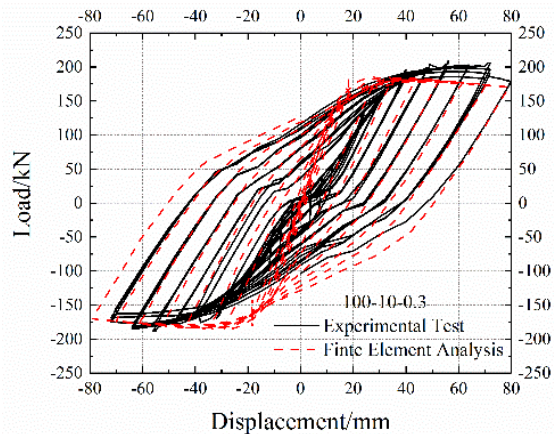

(a) $100-10-0.3$

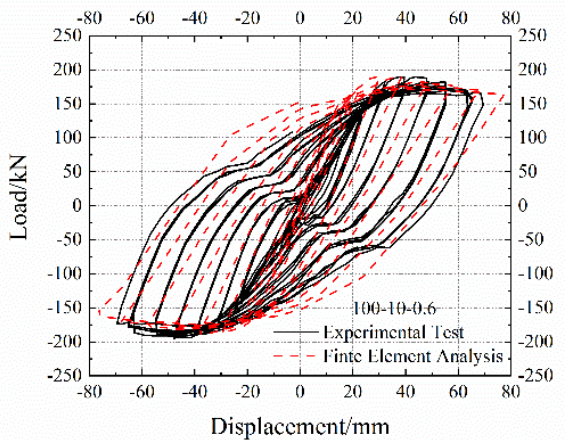

(b) $100-10-0.6$

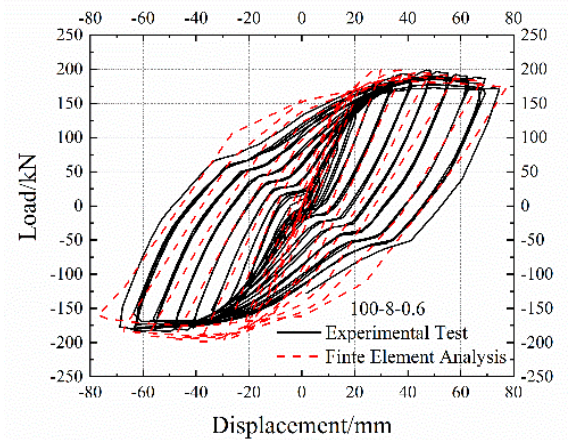

(c) $100-8-0.6$

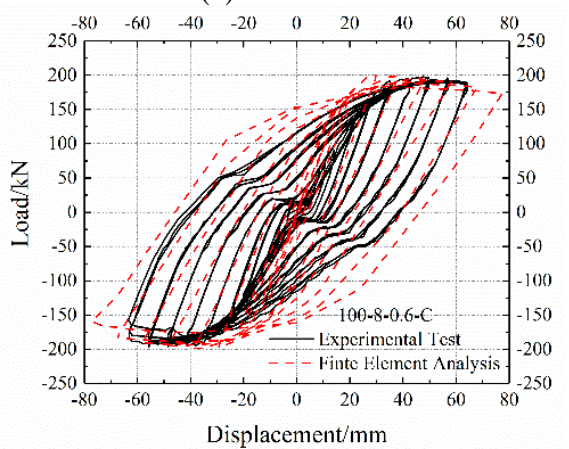

(d) $100-8-0.6-\mathrm{C}$ 


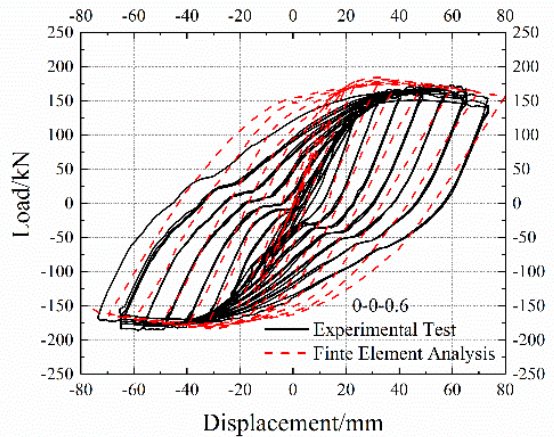

(e) $0-0-0.6$

Figure 7 Hysteretic curves

\subsection{Skeleton Curves}

The skeleton curve of each specimen has basically similar trend, which consists of three stages: elastic stage, plasticity strengthening stage and softening stage. The axial compression ratio is increased from 0.3 to 0.6 , the peak lateral load changes little, but the flexural capacity improves, because the constraint effect of FRP on UHPC core columns is excited earlier under high axial compression ratio. With the increase of lateral displacement, concrete cracking leads to the enhancement of constraint effect, the bending moment of joints is increasing, and the P- $\Delta$ effect is getting stronger, which leads to the growth of peak load reaching the bottleneck and thus the softening stage starts. As shown in Figure 8.

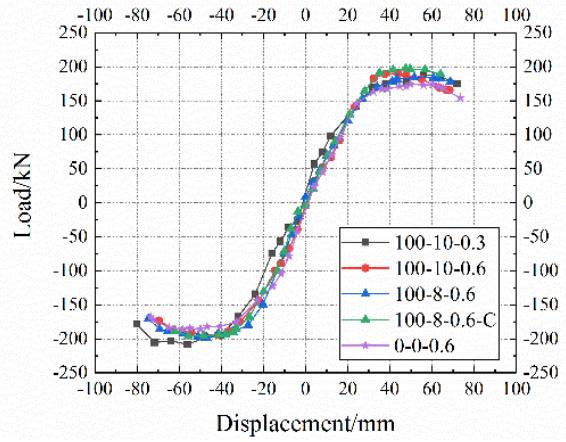

(a) Load-displacement skeleton curve

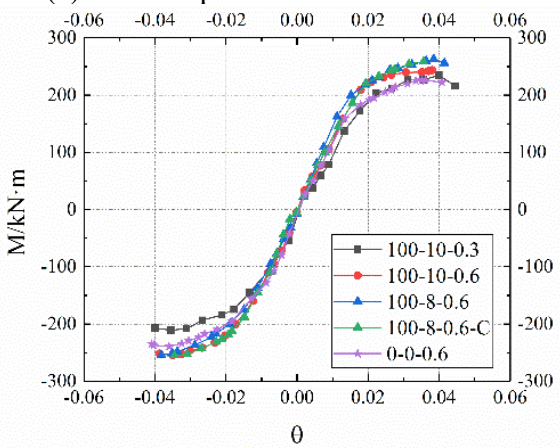

(b) Moment-angle skeleton curve

Figure 8 Skeleton curves

\subsection{Ductility and Energy Dissipation}

Table 4 shows the ductility coefficient of each specimen. Except for the replacement beam, the ductility coefficient of all the other specimens is greater than 2 . The ductility of specimens with high axial compression ratio is lower, which is due to the fact that specimens with high axial compression ratio bear more bending moments. Moreover, the constraint

Table 4 Ductility coefficient

\begin{tabular}{|c|c|}
\hline Specimen No. & $\bar{\mu}$ \\
\hline $100-10-0.3$ & 2.50 \\
\hline $100-10-0.6$ & 2.28 \\
\hline $100-8-0.6$ & 2.24 \\
\hline $100-8-0.6-\mathrm{C}$ & 1.59 \\
\hline $0-0-0.6$ & 2.56 \\
\hline
\end{tabular}

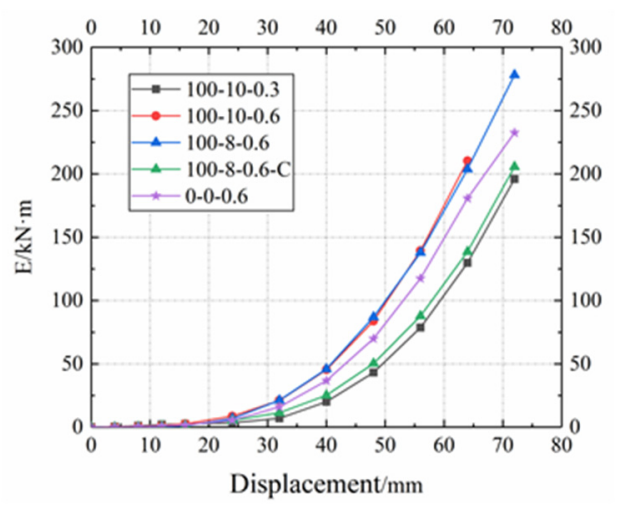

Figure 9 Cumulative energy dissipation

effect of FRP pipe and steel pipe in the joint area is excited earlier under high axial compression, and after the peak load, the constraint fails in advance, resulting in premature failure. Due to the plastic damage and concrete cracking of FRP-UHPC columns after the first loading, the ductility coefficient of specimens after replacing beams is lower than that of original specimens. The number of FRP layers has no significant influence on the ductility coefficient.

Figure 9 shows the cumulative energy dissipation per stage of each specimen. It can be seen from the figure that when loading at the same stage $(\Delta=64 \mathrm{~mm})$, the axial compression ratio increases from 0.3 to 0.6 , and the cumulative energy dissipation increases by $61.5 \%$, indicating that the axial compression ratio has a significant impact on the energy dissipation capacity and the energy dissipation capacity of the core column is also obviously improved.

\section{Conclusions}

Through the seismic test of Concrete-filled square steel tube column with core column -Steel Beam Joints, the following results are obtained:

- This kind of joint can work well under high axial compression ratio and has good seismic hysteretic 
performance. At the same time, most parts of the joint can be prefabricated in the factory, which improves the construction efficiency.

- The inter-story drift is between $1 / 29$ and $1 / 22$ when each specimen is damaged, which is far beyond the specification limit. It proves that the concrete-filled steel tubular column-steel beam joints with core columns has good collapse resistance capacity.

- The bearing capacity and energy dissipation capacity of the replacement beam specimen are good, which proves that the joint is removable and repairable after earthquake.

\section{Project fund}

This article is one of the phased results of the " 13th Five-Year Plan" national key research and development plan "Research on the mechanical properties and design methods of ultra-high performance concrete core-column members and beam-column joints confined by built-in winding pipes" (2017YFC0703004).

\section{References}

1. Li, G Q., Shi, W L., Wang, J F. (2009) Design of steel frames with semi-rigid connections. China Architecture \& Building Press, Beijing.

2. Zong, Z H., Lin, Y D., Chen, H W., Ge, J P., Yang, Q Y. (2005) Pseudo-static test study on connection between concrete-filled square steel tube columns and steel beams. Journal of Building Structures, 01: 77-84.

3. Wang, X T., Hao, J P., Zhou, G G. (2009) Research on the hysteretic performance of concrete-filled square steel tube cored high-strength bolt-end plate joints. Progress in Building Steel Structures, 11(01): 33-37.

4. National Standard of the People's Republic of China. (2015) Reactive Powder Concrete. China Construction Industry Press, Beijing. 